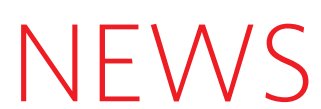

\title{
Upbeat oil report questioned
}

\section{Researchers see major uncertainties in Deepwater Horizon spill assessment.}

After months of gloom, last week's report on the fate of the oil from BP's Deepwater Horizon spill offered a rare piece of good news. "At least $50 \%$ of the oil that was released is now completely gone from the system," said Jane Lubchenco, administrator of the National Oceanic and Atmospheric Administration (NOAA), at a White House press conference on 5 August. That welcome figure came from an effort to tally what has happened to the three-quarters of a billion litres of oil that have poured into the Gulf of Mexico since April.

But although researchers have embraced some of the report's messages, many contacted by Nature point out that it fails to convey the substantial uncertainties in some of its estimates. "In my mind it's scientifically indefensible," says James Cowan, an oceanographer at Louisiana State University in Baton Rouge. Some question whether the timing of the report, released as BP announced that it had succeeded in plugging the damaged well, was driven more by politics than science.

The report estimates that about a quarter of the spilled oil was captured, burned or skimmed off the ocean; that another quarter was dispersed into tiny droplets, either naturally or with chemical dispersants; and that a quarter evaporated or completely dissolved. The remaining quarter, determined by subtraction, is assumed to be floating on the ocean's surface or already washed ashore (see graphic). Most of this remainder "is degrading rapidly or is being removed from the beaches", said Lubchenco, adding that there was a "high degree of confidence" in the numbers. She cautioned, however, that dissolved or dispersed oil could still pose threats to marine life.

Cowan isn't persuaded by this accounting. "There's not enough information in there to make anybody with any kind of quantitative or ecological background believe it," he says. Jeffrey Short, an environmental chemist based in Juneau, Alaska, believes that estimates of oil collection, skimming and burning should be reliable because they are directly measurable. But with relatively few data to call on, estimates of how much oil has dissolved, dispersed or evaporated could be off by factors of two to three, says Short, who works with the conservation-advocacy group Oceana and helped lead the damage assessment of the 1989 Exxon Valdez oil spill before he retired from NOAA.

Bill Lehr, a senior scientist with NOAA's emergency-response division and a lead

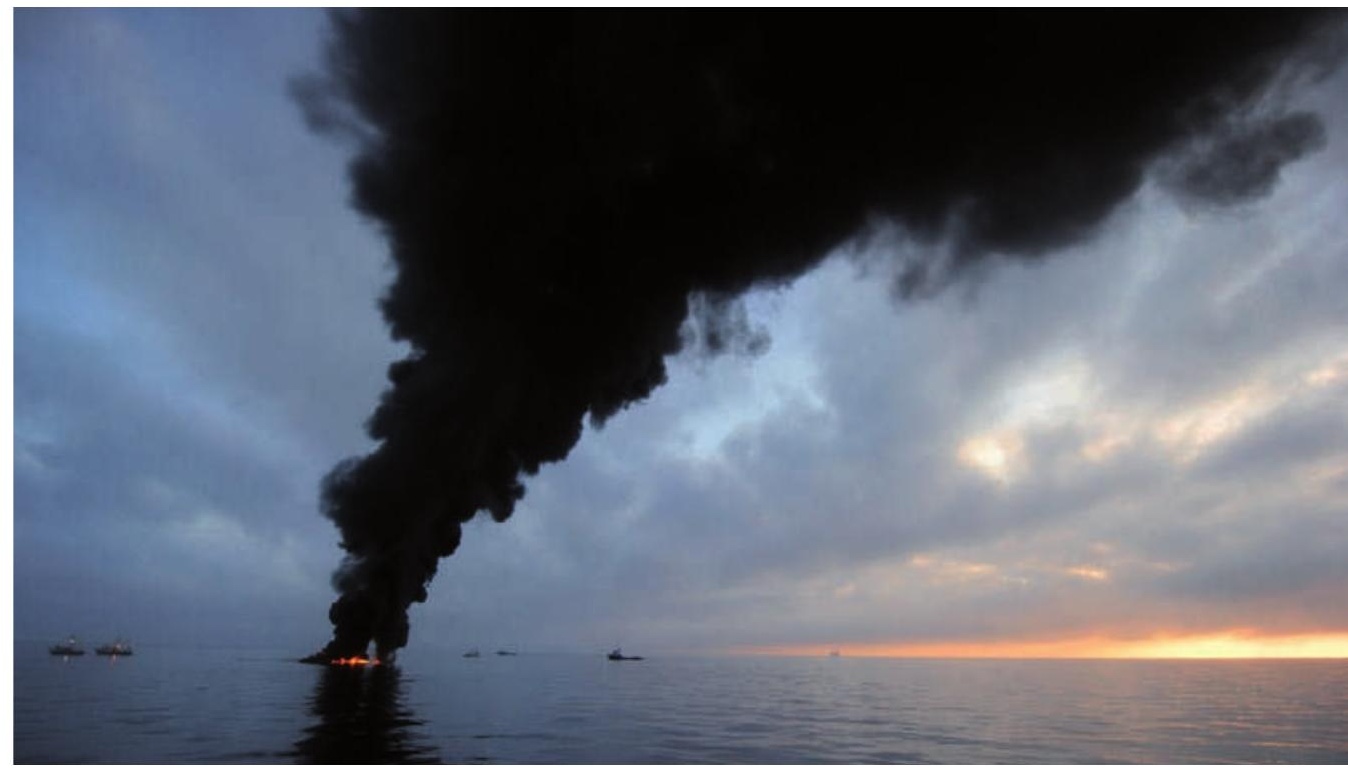

Controlled burning has helped to remove some of the Deepwater Horizon oil — but how much remains?

author of the report, agrees that these are the least certain numbers, but says that he and his colleagues intentionally used conservative estimates. Yet neither the report nor its supporting data mention the scale of the uncertainties, and there are scant details about how the numbers were calculated.

Lehr says that the oil budget calculator that produced the estimates has been used by the US Coast Guard since June to guide the spill response, and that the Coast Guard's version includes details on uncertainties. But for the public release, he says: "The decision was made - and people can argue whether that was right or not - to present the average values [without the uncertainties]."

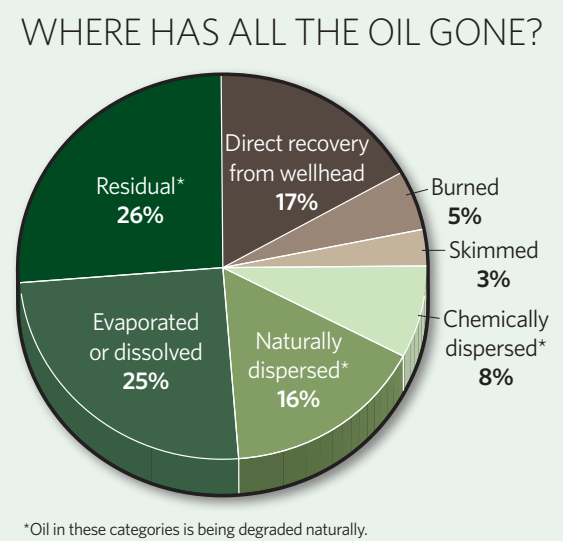

"The tool was there so we just decided this would help to answer some of the questions that the public had," he says. Lehr adds that the agency will be working to complete a report filling in the scientific details as quickly as it can.

But Short sees politics behind the report's release. "It has the feel that they're trying to make it coincide with killing the continued leaking and kind of put a ribbon on this," he says. Cowan adds that the report could help to restore confidence in the devastated Gulf seafood industry.

Many scientists agree that the biological toll of the spill in coastal areas seems to be lighter than feared. "Overall, I think most of us in the field agree that the impacts that have come to light so far are less horrific than we feared initially, largely because relatively little oil has gotten ashore," says Short. But the impact of dispersed or otherwise submerged oil on the young of marine species remains an open question. "Our concern is that we may lose an entire generation of fish, shrimp, oysters and crabs," says Deano Bonano, the homeland-security chief for Jefferson Parish, one of Louisiana's hardest-hit areas.

"The report made it sound very much like we were already over the hump," adds Cowan. "There are some big questions I'd like to see addressed before we can confidently say we're over the hump."

Mark Schrope 